\title{
Incidence and short outcome in multiple pregnancies: a single center cross- sectional study in Iran 2016-2017
}

\author{
Behnaz Basiri, ${ }^{1}$ Mohammad Kazem Sabzehei, ${ }^{1}$ Maryam Shokouhi, ${ }^{1}$ Mohammad Mahdi Sabahi ${ }^{2}$
}

pISSN: 0853-1773 • elSSN: 2252-8083 https://doi.org/10.13181/mji.v28i1.2827 Med J Indones. 2019;28:28-34

Received: May 8, 2018

Accepted: February 23, 2019

Author's affiliations:

${ }^{1}$ Department of Pediatrics, Hamadan University of Medical Sciences and Health Services, Hamadan, Iran ${ }^{2}$ Student Research Committee, Faculty of Medicine, Hamadan University of Medical Sciences and Health Services, Hamadan, Iran

Corresponding author: Mohammad Mahdi Sabahi

Student Research Committee, School of Medicine, Hamadan University of Medical Sciences, Shahid Fahmideh Street, Hamadan 65178/518, Iran Tel: +98-9384275407

E-mail: mmsabahi1996@gmail.com

\begin{abstract}
BACKGROUND The incidence of multiple pregnancies in industrialized countries due to the use of assisted reproductive techniques has increased over the past two decades. Multiple births are more dangerous than single pregnancies for mother and baby. This study evaluated the frequency of multiple pregnancies and its neonatal complications.
\end{abstract}

METHODS In this cross-sectional study, we assessed all multiple neonates hospitalized in Fatemieh Hospital of Hamadan, Iran from September 2016 to September 2017 in terms of gender, gestational age, birth weight, the use of assisted reproductive techniques, delivery method, cause of hospitalization, therapeutic intervention, and hospitalization outcome.

RESULTS Of 10,581 deliveries during the study period, 351 (3.3\%) were multiple pregnancies and 232 neonates were hospitalized. The incidence of twin, triplet, and quadruplet birth were $1.7 \%, 0.39 \%$, and $0.11 \%$ respectively. In this study, 178 twin and 54 triplet and quadruplet birth were compared. The mean gestational age and mean birth weight of triplet and quadruplet were lower than that of twin births $(p<0.001)$. A significant difference was found on the frequency of assisted reproductive techniques $(p<0.001)$. Female sex $(p=0.007)$, lower mean gestational age $(p=0.009)$, lower mean birth weight $(p=0.017)$ and need to mechanical ventilation $(p<0.001)$ were significantly associated with early neonatal death in multiple pregnancies.

CONCLUSIONS The incidence of multiple births was high in the Hamadan province, which was often followed by infertility treatment. Moreover, multiple births cause prematurity, low birth weight, respiratory distress syndrome, and increased neonatal mortality rate.

KEYWORDS incidence, multiple pregnancy, pregnancy outcome
During the two past decades, the frequency of twin pregnancies in industrialized countries has increased. The most important factor contributing to it is increased usage of assisted reproductive techniques (ART) and aging of the mothers. ${ }^{1-3}$ The multiple pregnancies rate includes about $3 \%$ of births and $14 \%$ of infant mortalities that are rising day by day. ${ }^{3}$ Approximately two-thirds of twins are dizygotic. ${ }^{2}$ With the increase of maternal age, the probability of dizygotic twin is also increased.
Twin pregnancies rate in America has increased about $75 \%$ from 1980 to 2009. A similar increase has also been reported in Western Europe and other countries. ${ }^{4,5}$ The dizygotic twin rate varies in different countries and different factors such as race (10-40 per 1,000 births in blacks, 7-10 per 1,000 births in whites, and approximately 3 per 1,000 births in Asians), maternal age (the frequency has risen with increasing maternal age $\leq 40$ years), heredity, the number of labors, and 
the usage of ART. ${ }^{2,6}$ The incidence of monozygotic twins is constant worldwide, approximately four per 1,000 births. Naturally occurring triplet births occur in approximately 1 per 7,000-10,000 births; meanwhile, naturally occurring quadruplet births occur in approximately 1 per 600,000 births. ${ }^{2}$

Twin birth is of high-risk pregnancies because of its effect on increasing the mortality rate among mothers and neonates. Gestational age at the birth time and the weight differences are the most important independent predictor factors about mortality and complications associated with twin birth.7 According to the researches, maternal complications such as premature birth, preeclampsia, polyhydramniosis, premature rupture of membranes, previa vessels (vasa previa), hyperemesis gravidarum, membrane attachment umbilical cord, abnormal presentation (breech) and preterm delivery (preterm labor), and the risk of intrauterine growth restriction and neonatal complications such as neonatal death, preterm birth, low birth weight, respiratory distress syndrome (RDS), hypoglycemia, hypocalcemia, and no correspondence between the weights of twins and twin-to-twin transfusion syndrome have increased in multiple births than in singleton births.8,9 According to the latest statistics about the frequency of newborn twins in Hamadan in 1996, Riazi and colleagues reported that the prevalence of multiple births was about $5.4 \% .^{10}$ Also, new data about the prevalence of multiple births and their complications and about rising of infertility among women and the usage of new methods to induce pregnancy and their effects on multiple births in Hamadan are not available. This study aimed to determine the prevalence and short outcome of multiple births in Fatemieh Hospital of Hamadan, Iran.

\section{METHODS}

\section{Study design and population}

This cross-sectional study was conducted by file reading. For this purpose, the data contained in the archive and information system of Fatemieh Hospital of Hamadan, Iran, from September 2016 to September 2017 were extracted. The keyword used in the electronic search of files included twin or multiple births in a specified time interval. The file numbers of multiple pregnant mothers were extracted and by referring to archive, their files were given, and data were recorded on the data sheet.

\section{Measuring tools}

Information about mothers and newborns was extracted from labor file. Recorded data were included the number of neonates, maternal age, gestation way (natural or induced), method of delivery, birth weight, gestational age, neonatal sex, maternal age, occurrence of sepsis, need for resuscitation, usage of mechanical ventilation, usage of antibiotics, usage of surfactant, and hospitalization outcomes. Respiratory distress was considered positive in infants that required respiratory support due to respiratory distress, such as supplemental oxygen, intubation, surfactant, and mechanical ventilation. The number of days spent by neonates in a neonatal intensive care unit or special care unit was considered as hospitalization time. Neonates born weight less than 1,500 g was named as very low birth weight (VLBW).

\section{Ethical consideration}

All procedures performed in studies involving human participants were in accordance with the ethical standards of the institutional Hamadan University of Medical Sciences (code: IR.UMSHA.REC.1394.454) and with the 1964 Helsinki declaration and its later amendments or comparable ethical standards. For this type of study, formal consent is not required.

\section{Inclusion and exclusion criteria}

Inclusion criteria included all pregnant women with gestational age between 25-36 weeks of gestation and labors that occurred before 25 weeks of gestation. Outside delivery and incomplete records were excluded from the study.

\section{Data analysis}

Collected data were analyzed using the statistical package for the social sciences (SPSS, version 16.0, SPSS Inc, Chicago, Illinois, USA). Data were reported as below: qualitative variables by number and percentage, quantitative variables by mean and standard deviation (SD), the correlation between variables by chi-square test, and the comparison of quantitative variables (mean) by t-test. Significance level was considered as $\mathrm{p}<0.05$.

\section{RESULTS}

Of 10,851 delivery during considered period, 351 mothers (3.3\%) had multiple births and 232 neonates 
Table 1. Perinatal characteristics of multiple pregnancies

\begin{tabular}{|lc|}
\hline Characteristics & Outcomes, $\mathrm{n}(\%)$ \\
\hline Gender & $142(61.2)$ \\
\hline Male & $90(38.8)$ \\
\hline Female & $31.9(2.9)$ \\
\hline Gestational age (weeks)* & $1,647(535)$ \\
\hline Birth weight (g)* & $23.1(4.6)$ \\
\hline Maternal age (years)* & $224(96.5)$ \\
\hline Preterm delivery & \\
\hline Multiple & $178(76.8)$ \\
\hline Twin & $42(18.1)$ \\
\hline Triplet & $12(5.1)$ \\
\hline Quadruplet & $8(3.5)$ \\
\hline Mode of delivery & $224(96.5)$ \\
\hline NVD & \\
\hline Cesarean & $63(27.1)$ \\
\hline ART & $14(6)$ \\
\hline IVF & $83(35.7)$ \\
\hline IUI & $34(14.7)$ \\
\hline VLBW & $193(83.2)$ \\
\hline Sepsis & $58(25)$ \\
\hline RDS & $114(49.1)$ \\
\hline Need to mechanical ventilation & $60(25.9)$ \\
\hline Type of treatment & $26(11.2)$ \\
\hline Antibiotic alone & $32(13.8)$ \\
\hline Surfactant and antibiotic & $11.3(10.0)$ \\
\hline Ventilator and antibiotic & \\
\hline
\end{tabular}

*Data are presented as mean (SD). NVD=normal vaginal delivery; ART=assisted reproductive technology; IVF=in vitro fertilization; IUI=intrauterine insemination; VLBW=very low birth weight; RDS=respiratory distress syndrome

hospitalized. The incidence of twin, triplet, and quadruplet birth were $1.7 \%$ (178), $0.39 \%$ (42) and $0.11 \%$ (12) respectively. The mean (SD) of perinatal characteristics of multiple pregnancies are 31.9 (2.9) weeks for gestational age and 1,647 (535) g for birth weight of and 119 of newborns were not admitted to the neonatal intensive care unit (due to gestational age $>34$ and birth weight $>1,800 \mathrm{~g}$ ). Among 232 multiple infants hospitalized during the study period, 178 infants (76.8\%) were twins, 42 infants (18.1\%) were triplets, and 12 infants (5.1\%) were quadruplets (Table 1). The mean gestational age and mean birth weight of triplet and quadruplet were lower than that of twin births ( $p<0.001)$. In most of the twin births, conception was performed by natural method ( $82(2 \%))$, but in 58 (5\%) of triplets and $100 \%$ of quadruplets, IVF was the way of pregnancy occurrence. IUI method was used in $2.8 \%$ and $17 \%$ of twins and triplets and quadruplets. Statistically significant difference was observed in contraception method $(p=0.001)$. The types of medical management received such as receiving antibiotics, ventilator, and surfactant were shown in Table 2. In this study, no significant relationship was observed between the number of twins and the type of medical management $(p=0.549)$. Age distribution among mothers with multiple births is shown in Table 2 according to the number of twins. The mean (SD) of age for hospitalized mothers with multiple births was 23.1 (4.6) year (minimum 14 and maximum 35 years). The relationship between mean age of mothers and twin birth was statistically significant $(p=0.001)$. Among all of the causes of multiple-born infants hospitalization in Table 2, there was a significant relationship between prematurity $(p<0.001)$ and VLBW $(p=0.033)$ with the number of twins. The short outcome of multiple births was examined (Table 3). The results showed that $86.6 \%$ of neonates had survived and $13.4 \%$ of neonates had died. According to the results of chi-square test, no significant difference was observed between the number of twins and hospitalization outcomes $(p=0.239)$. Female sex $(p=0.007)$, lower mean gestational age $(p=0.009)$, lower mean birth weight $(p=0.017)$, and the need to mechanical ventilation $(p<0.001)$ were significantly associated with early neonatal death in multiple pregnancies. Statistically significant difference was observed in complication rate by a decrease in gestational age in multiple pregnancies (Table 4). In this study, 38 of twins were monozygotic and 194 were dizygotic. The need for mechanical ventilation and VLBW were significantly higher in monozygotic twins (Table 5).

\section{DISCUSSION}

Multiple-gestation pregnancies are more associated with a significantly higher maternal complication rate than singleton gestations. Multiplegestation pregnancies carry an increased risk of hypertensive disorders of pregnancy; gestational diabetes mellitus; hyperemesis; preterm labor; premature rupture of membranes; anemia; placental abruption; postpartum hemorrhage; cardiac 
Table 2. Comparison of perinatal characteristics of multiple pregnancies

\begin{tabular}{|c|c|c|c|}
\hline Characteristics & Twin, $n(\%)(n=178)$ & Triplet and quadruplet, $n(\%)(n=54)$ & $\mathrm{p}$ \\
\hline Gender & & & 0.440 \\
\hline Male & $106(59.0)$ & $36(66.7)$ & \\
\hline Female & $72(41.0)$ & $18(33.3)$ & \\
\hline Gestational age $<37$ (weeks) & $170(95.5)$ & $54(100)$ & 0.293 \\
\hline Gestational age (weeks)* & $32.4(2.9)$ & $30.3(2.5)$ & $<0.001$ \\
\hline Birth weight $(\mathrm{g})^{*}$ & $1,699(552)$ & $1,468(429)$ & 0.006 \\
\hline Maternal age* & $23.4(4.8)$ & $22.1(3.2)$ & $<0.001$ \\
\hline Mode of delivery & & & 0.484 \\
\hline NVD & $8(4.5)$ & $0(0)$ & \\
\hline Cesarean & $170(95.5)$ & $54(100)$ & \\
\hline ART & & & $<0.001$ \\
\hline IVF & $27(15.1)$ & $36(66.6)$ & \\
\hline IUI & $5(2.8)$ & 9 (16.6) & \\
\hline VLBW & $56(31.5)$ & $27(50.0)$ & 0.033 \\
\hline Sepsis & $25(14.0)$ & 9 (16.6) & 0.586 \\
\hline RDS & $146(82.0)$ & $47(87.0)$ & 0.224 \\
\hline Need to mechanical ventilation & $45(25.2)$ & $13(24.0)$ & 0.928 \\
\hline Type of treatment & & & 0.549 \\
\hline Antibiotic alone & $92(51.6)$ & $22(40.7)$ & \\
\hline Surfactant and antibiotic & $41(23.0)$ & $19(35.2)$ & \\
\hline Ventilator and antibiotic & $21(11.8)$ & $5(9.2)$ & \\
\hline Ventilator and surfactant and antibiotic & $24(13.5)$ & $8(14.8)$ & \\
\hline Length of stay (days)* & $10.9(10.1)$ & $12.6(9.5)$ & 0.285 \\
\hline Neonatal death & $26(14.6)$ & $5(9.2)$ & 0.339 \\
\hline
\end{tabular}

*Data are presented as mean (SD). NVD=normal vaginal delivery; ART=assisted reproductive technology; IVF=in vitro fertilization; IUI:intrauterine insemination; VLBW=very low birth weight; RDS=respiratory distress syndrome complications; operative deliveries, both vaginal and cesarean; required hysterectomy; and prolonged hospital stay. The increase in fetal and neonatal morbidity and mortality associated with multiple gestation/birth pregnancies correlates with an increased risk of preterm delivery, low birth weight, and intrauterine growth retardation. ${ }^{2}$

In this study, among 10,851 labors over one year, 351 cases of multiple births (3.3\%) were observed. In a study by Rezavand et al ${ }^{11}$ of 29,438 deliveries performed from 2004 to 2007, the frequency of twin pregnancy was found out to be 1 in 208 cases (4.8\%). According to the report published in 2016, the rate of multiple births in European countries was calculated 1.68 per 100 births on average in which the maximum and minimum rates of multiple births were dedicated to Cyprus (26.5 per 1,000 births) and Romania (9.1 per 1,000 births) respectively. ${ }^{12}$

Other reports showed that from 2004 to 2010 , the rate of twinning in European Union increased by $1.7 \%$ and reached $12.5 \%$ in live births. However, the rate of triplet births has been increased percent and reached 0.3 per 1,000 live births. The highest rate of triplet births in European countries belonged to Malta with 1.5 births per 1,000 live births. ${ }^{13}$ Wei et $\mathrm{al}^{3}$ conducted a cross-sectional study that included 3,246 women with multiple gestation pregnancies and who had multiple live-birth deliveries; the women were registered at ten maternal-fetal medicine centers in China in 2013. They reported that the incidence of multiple births in China was rising. ${ }^{3}$ The incidence of multiple births of our study was $3.3 \%$, higher than previous studies and the same study in Pakistan ${ }^{8}$ with $3.7 \%$. The reason for the difference was that our review was carried out in a provincial tertiary hospital. Preterm delivery is an important consequence of multiple pregnancies, ranging from $5-50 \%$ around the world. ${ }^{14}$

The average gestational age for twin deliveries is 35.3 weeks; for triplet deliveries, 32.2 weeks; and for quadruplet deliveries, 29.9 weeks. ${ }^{2}$ In Wei's study, 
Table 3. Perinatal outcomes of multiple pregnancies

\begin{tabular}{|c|c|c|c|}
\hline \multirow[b]{2}{*}{ Characteristics } & \multicolumn{2}{|c|}{ Outcomes } & \multirow[b]{2}{*}{$p$} \\
\hline & $\begin{array}{c}\text { Survive, } n(\%) \\
\quad(n=201)\end{array}$ & $\begin{array}{l}\text { Died, } n(\%) \\
\quad(n=31)\end{array}$ & \\
\hline Gender & & & 0.007 \\
\hline Male & 130 (64.7) & $12(38.7)$ & \\
\hline Female & $71(35.3)$ & $19(61.3)$ & \\
\hline $\begin{array}{l}\text { Gestational age }<37 \\
\text { (weeks) }\end{array}$ & 200 (99.5) & $24(77.4)$ & 0.303 \\
\hline $\begin{array}{l}\text { Gestational age } \\
\text { (weeks)* }\end{array}$ & $32.1(2.8)$ & 31.1 (3.7) & 0.009 \\
\hline Birth weight $(\mathrm{g})^{*}$ & $1,682(512)$ & $1,421(628)$ & 0.017 \\
\hline Multiple & & & 0.239 \\
\hline Twin & $152(75.6)$ & 26 (83.9) & \\
\hline $\begin{array}{l}\text { Triplet and } \\
\text { quadruplet }\end{array}$ & $49(24.4)$ & $5(16.1)$ & \\
\hline Maternal age* & $23.3(4.7)$ & $22(3.5)$ & 0.054 \\
\hline Mode of delivery & & & 0.289 \\
\hline NVD & $8(4.0)$ & $0(0.0)$ & \\
\hline Cesarean & $193(96.0)$ & $31(100)$ & \\
\hline ART & & & 0.392 \\
\hline IVF & $57(28.3)$ & $6(19.4)$ & \\
\hline IUI & $13(6.5)$ & $1(3.2)$ & \\
\hline VLBW & $69(34.3)$ & $14(45.1)$ & 0.900 \\
\hline Sepsis & $31(15.4)$ & $3(9.7)$ & 0.569 \\
\hline RDS & $166(82.6)$ & $27(87.0)$ & 0.532 \\
\hline $\begin{array}{l}\text { Need to mechanical } \\
\text { ventilation }\end{array}$ & $41(20.4)$ & $17(54.8)$ & $<0.001$ \\
\hline $\begin{array}{l}\text { Length of stay } \\
\text { (weeks)* }\end{array}$ & $11.8(10.1)$ & $7.6(8.3)$ & 0.491 \\
\hline
\end{tabular}

*Data are presented as mean (SD). NVD=normal vaginal delivery; ART=assisted reproductive technology; IVF=in vitro fertilization; IUI:intrauterine insemination; VLBW=very low birth weight; RDS=respiratory distress syndrome

the preterm delivery rate was $29.5 \% .^{3}$ In this study, the frequency of preterm delivery was $96.5 \%$ that was higher than European countries that were evaluated 53.4\% for multiple births. Cyprus and Austria with 66\% have the most and Latvia and Denmark with $40 \%$ have the lowest rate of preterm labor among European countries. ${ }^{15}$

Birth weight is closely associated with gestational age, so the increased incidence of preterm delivery influences the rate of reduced birth weights in multiple-birth neonates. These neonates also have an increased incidence of intrauterine growth retardation. ${ }^{2}$ In this study, the mean (SD) birth weight was 1,647 (535) g. In this study, the cesarean delivery rate was $96.5 \%$, similar to Sua's study with $85.8 \%$, which showed the highest cesarean rate in multiple births. ${ }^{14}$ Therefore, the American College of Obstetricians and Gynecologists published new recommendations for the management of delivery methods to reduce cesarean section rates. ${ }^{16} \mathrm{~A}$ study by Mesa et al ${ }^{17}$ showed that the length of hospitalization, hospital costs, and the rate of cesarean section in women who had a multiple pregnancies were higher than women with a singleton pregnancy. In more than $50 \%$ of women, labor was performed by cesarean section. Hospital costs of multiple pregnancies women were higher 30-50 times than women with a singleton pregnancy. The researchers concluded that multiple births were effective on maternal and infant mortality in addition to the economic costs. They suggested that infertility specialists should adopt advanced treatment protocols to induce artificial singleton pregnancy.

The results of studies showed that the usage of ART in women with older ages was more likely and therefore, their likelihood of multiple births increased. ${ }^{18-20}$ In this study, the majority of the twin pregnancies was occurred by natural conception ( $82 / 2 \%$ ), but in triplet births (58/5\%) and quadruplet births (100\%), IVF was mainly the method of pregnancy. Furthermore, a significant difference was observed between the conception method and the number of twins $(p=0.001)$. From three decades ago and after the discovery of ART, the usage of these methods caused a significant increase in multiple births rate. Also, according to the report of American Society for Reproductive Medicine, ${ }^{21}$ one of the most risk factors of multiple births is the usage of modern methods of infertility treatment. IVF and nonIVF fertility methods (including induction of ovarian and stimulation of ovule release) are the main risk factors for multiple births (twins, triplets, or higher). ${ }^{22}$ In fact, one of the adverse consequences of infertility treatment is the incidence of multiple births in such, the usage of these techniques increased triplet births or higher-order multiple births. ${ }^{23-25}$ In this study, the majority of triplet pregnancies and all of the quadruplet pregnancies were taken place by IVF.

In one sectional study by Qazi et $\mathrm{al}^{8}$ that was performed on hospital files in Peshawar, Pakistan, the incidence of multiple births has been reported 37.1 per thousand live births (3.7\%). Neonatal complications in this group included: low birth weight (LBW) (13/7\%), VLBW (6\%), Apgar score less than 7 at 5 min (27.5\%), need to be hospitalized in neonatal intensive care unit 
Table 4. Complications rate based on the gestational age

\begin{tabular}{|c|c|c|c|c|c|}
\hline Characteristics & $\begin{array}{l}\text { Term } \\
(\geq 37)\end{array}$ & $\begin{array}{l}\text { Late preterm } \\
\qquad(34-36)\end{array}$ & $\begin{array}{l}\text { Very preterm } \\
(29-33)\end{array}$ & $\begin{array}{l}\text { Extreme preterm } \\
\qquad(\leq 28)\end{array}$ & $p$ \\
\hline Sepsis & & & & & 0.005 \\
\hline Yes & $4(1.7)$ & $10(4.3)$ & $20(8.6)$ & $0(0)$ & \\
\hline No & $4(1.7)$ & $51(22.0)$ & $118(50.9)$ & $25(10.8)$ & \\
\hline RDS & & & & & 0.006 \\
\hline Yes & $4(1.7)$ & $46(19.8)$ & $118(50.9)$ & $25(10.8)$ & \\
\hline No & $4(1.7)$ & $15(6.5)$ & $20(8.6)$ & $0(0)$ & \\
\hline VLBW & & & & & 0.001 \\
\hline Yes & $0(0)$ & $7(3.0)$ & $51(22.0)$ & $25(10.8)$ & \\
\hline No & $8(3.4)$ & $54(23.3)$ & 87 (37.5) & $0(0)$ & \\
\hline Type of treatment & & & & & 0.003 \\
\hline Antibiotic alone & $5(2.2)$ & 43 (18.9) & $56(24.1)$ & $10(4.3)$ & \\
\hline Surfactant and antibiotic & $2(0.9)$ & $7(3.1)$ & $42(18.4)$ & $9(3.9)$ & \\
\hline Ventilator and antibiotic & $1(0.4)$ & $8(3.5)$ & $14(6.1)$ & $3(1.3)$ & \\
\hline Ventilator and surfactant and antibiotic & $0(0.0)$ & $3(1.3)$ & $26(11.4)$ & $3(1.3)$ & \\
\hline Neonatal death & $0(0)$ & $9(4.0)$ & $14(6.2)$ & $8(3.5)$ & 0.028 \\
\hline
\end{tabular}

Data presented as n (\%). RDS=respiratory distress syndrome; VLBW=very low birth weight

(9/8\%), RDS (7\%), birth asphyxia (7.8\%), sepsis (6.1\%), congenital anomalies (7\%), and perinatal death (17.2\%). The average age of mothers was reported 28.07 years old and among this, in $13 \%$ of cases, the pregnancy was occurred by artificial induction. This study was similar in some factors with the results of our study, in which LBW (22\%), VLBW (35.7\%), Apgar score less than 7 at $5 \mathrm{~min}(1.7 \%)$, RDS (83.2\%), sepsis (14.7\%) and the average age of mothers 23.1 ( 4.6 year) (33.1\% of them had become pregnant by artificial induction) were calculated. Female sex, lower mean gestational age, lower mean birth weight, and the need to mechanical ventilation were significantly associated with early neonatal death in our study. Previous studies in Iran showed that the most frequent complications of multiple births were prematurity, LBW, respiratory distress syndrome, and increased neonatal mortality rate. These findings were consistent with our results. ${ }^{26,27}$

The most common causes of hospitalization of twins and triplets in this study were the respiratory distress syndrome ( $82 \%$ and $87 \%$ ), VLBW (31.5\% and $50.0 \%$ ), and sepsis (14\% and $17 \%$ ). In Mosayebi's study, the most common causes of hospitalization were prematurity, icter, sepsis, and hypoglycemia. ${ }^{28}$ In a study conducted by Faraji et al, ${ }^{6}$ the most common causes of hospitalization were LBW and congenital anomalies.

Study of mortality rate and its comparison with the countries of the euro-zone resulted that the
Table 5. Comparison of perinatal characteristics of monozygotic vs. dizygotic twins

\begin{tabular}{lccc}
\hline Characteristics & $\begin{array}{c}\text { Monozygotic, } \\
\mathrm{n}(\%) \\
(\mathrm{n}=38)\end{array}$ & $\begin{array}{c}\text { Dizygotic, } \\
\mathrm{n}(\%) \\
(\mathrm{n}=194)\end{array}$ & $\mathrm{p}$ \\
\hline Gender & $22(57.9)$ & $120(61.8)$ & 0.771 \\
\hline Male & $16(42.1)$ & $74(38.2)$ & \\
\hline Female & $24(63.2)$ & $59(30.4)$ & $<0.001$ \\
\hline $\begin{array}{l}\text { VLBW } \\
\text { Sepsis }\end{array}$ & $5(13.2)$ & $29(14.9)$ & 0.777 \\
\hline RDS & $27(71.1)$ & $166(85.5)$ & 0.225 \\
\hline $\begin{array}{l}\text { Type of treatment } \\
\text { Antibiotic alone }\end{array}$ & $14(38.9)$ & $100(51.5)$ & 0.021 \\
\hline $\begin{array}{l}\text { Surfactant and } \\
\text { antibiotic }\end{array}$ & $9(23.0)$ & $51(26.3)$ & \\
\hline $\begin{array}{l}\text { Ventilator and } \\
\text { antibiotic }\end{array}$ & $5(13.1)$ & $21(10.8)$ & \\
\hline $\begin{array}{l}\text { Ventilator and } \\
\text { surfactant and } \\
\text { antibiotic }\end{array}$ & $10(27.8)$ & $22(11.5)$ & \\
\hline $\begin{array}{l}\text { Length of stay } \\
\text { (days) }\end{array}$ & $11.7(13.4)$ & $11.3(9.4)$ & 0.098 \\
\hline Neonatal death & $8(21.1)$ & $23(11.9)$ & 0.128 \\
\hline
\end{tabular}

*Data are presented as mean (SD). VLBW=very low birth weight; RDS=respiratory distress syndrome 
mortality rate of multiple births in our hospital (13.4\%) was higher than in European countries (1.46\%). Among these countries, Romania, Luxembourg, and Northern Ireland had the highest rate (2.6\%) and Estonia had the lowest rate $(0.44 \%)$ of death among neonates of multiple births. ${ }^{29}$ The difference was because, in our study, mortality was evaluated in only hospitalized cases, not in all of the multiple births. Our findings were consistent with the results of other studies. ${ }^{8,30}$

The incidence of multiple births was high in the Hamadan province, which was often followed by infertility treatment. Moreover, multiple births cause prematurity, LBW, respiratory distress syndrome, and increased neonatal mortality rate.

\section{Conflict of Interest}

The authors affirm no conflict of interest.

\section{Acknowledgment}

We thank our colleagues and the staff of the neonatal ward of Fatemieh Hospital for their cooperation in implementing this project.

\section{Funding Sources}

None.

\section{REFERENCES}

1. Blondel B, Kaminski M. Trends in the occurrence, determinants, and consequences of multiple births. Semin Perinatol. 2002;26(2):239-49.

2. Garth E Fletcher, MD; Chief Editor: Ted Rosenkrantz, MD. Multiple birth, Medscape. Up-to-dated: Jan 13, 2015

3. Wei J, Wu QJ, Zhang TN, Shen ZQ, Liu H, Zheng DM, et al. Complications in multiple gestation pregnancy: a crosssectional study of ten maternal-fetal medicine centers in China. Oncotarget. 2016;7(21):30797-803.

4. Collins J. Global epidemiology of multiple birth. Reprod Biomed Online 2007;15 (Suppl 3):45-52.

5. Pison G, D'Addato AV. Frequency of twin births in developed countries. Twin Res Hum Genet 2006;9(2):250-9.

6. Faraji R, Asgharnia M, Zahiri Z, Dalil Heirati SF. Assessment of the frequency of twin pregnancies and its associated complications in Rasht's Alzahra Hospital during 1997-2002. Iran Surg J. 2012:19(4);15-22.

7. Chowdhury S, Hussain MA. Maternal complications in twin pregnancies. Mymensingh Med J. 2011;20(1):83-7.

8. Qazi G. Obstetric and perinatal outcome of multiple pregnancy. J Coll Physicians Surg Pak. 2011;21(3):142-5.

9. Choi SH, Park YS, Shim KS, Choi YS, Chang JY, Hahn WH, et al. Recent trends in the incidence of multiple births and its consequences on perinatal problems in Korea. J Korean Med Sci. 2010;25(8):1191-6.

10. Riazi H, Sadri Gh, Saeedi Jam M. The study of prevalence of low birth weight newborns in Hamadan's Maternity Hospital during the first 9 month of 1974. J Hayat. 2000;6(1): 52-9.

11. Rezavand N, Veisi F, Malek-khosravi Sh, Zangeneh M, Kohzadi M. Assessment of frequency of twin pregnancy and neonatal outcome in deliveries of Mo'tazedi Hospital, Kermanshah in 2004-2007. J Obstet Gynaecol India. 2014;64(1):19-22.

12. Bodeau-Livinec F, Zeitlin J, Blondel B, Arnaud C, Fresson J, Burguet $A$, et al. Do very preterm twins and singletons differ in their neurodevelopment at 5 years of age? Arch Dis Child Fetal Neonatal Ed. 2013;98(6):F480-7.

13. Mohangoo AD, Buitendijk SE, Szamotulska K, Chalmers J, Irgens LM, Bolumar F, et al. Gestational age patterns of fetal and neonatal mortality in Europe: results from the Euro-Peristat project. PLoS One. 2011;6(11):e24727.

14. Su RN, Zhu WW, Wei YM, Wang C, Feng H, Lin L, et al. Maternal and neonatal outcomes in multiple pregnancy: a multicenter study in the Beijing population. Chronic Dis Transl Med. 2015;1(4):197-202.

15. Blondel B, Macfarlane A, Gissler M, Breart G, Zeitlin J, PERISTAT Study Group. Preterm birth and multiple pregnancy in European countries participating in the PERISTAT project. BJOG. 2006;113(5):528-35.

16. American College of Obstetricians and Gynecologists (College), Society for Maternal-Fetal Medicine, Caughey AB, Cahill AG, Guise JM, Rouse DJ. Safe prevention of the primary cesarean delivery. Am J Obstet Gynecol. 2014;210(3):179-93.

17. Mesa EG, Peral JA. Incidence and costs of multifetal pregnancies in Andalusia (2000-2010). Twin Res Hum Genet. 2011;14(5):4849.

18. Tandberg A, Bjørge T, Børdahl PE, Skjaerven R. Increasing twinning rates in Norway, 1967-2004: the influence of maternal age and assisted reproductive technology (ART). Acta Obstet Gynecol Scand. 2007;86(7):833-9.

19. Russell RB, Petrini JR, Damus K, Mattison DR, Schwarz RH. The changing epidemiology of multiple births in the United States. Obstet Gynecol. 2003;101(1):129-35.

20. Scholten I, Chambers GM, van Loendersloot L, van der Veen F, Repping S, Gianotten J, et al. Impact of assisted reproductive technology on the incidence of multiple-gestation infants: a population perspective. Fertil steril. 2015;103(1):179-83.

21. Practice Committee of American Society for Reproductive Medicine. Multiple gestation associated with infertility therapy: an American society for reproductive medicine practice committee opinion. Fertil Steril. 2012;97(4):825-34.

22. Wright VC, Chang J, Jeng G, Macaluso M, Centers for Disease Control and Prevention (CDC). Assisted reproductive technology surveillance-United States, 2005. MMWR Surveill Summ. 2008;57(3):1-23.

23. Martin JA, Hamilton BE, Osterman MJ. Three decades of twin births in the United States, 1980-2009. NCHS Data Brief. 2012;(80):1-8.

24. Martin JA, Hamilton BE, Ventura SJ, Osterman MJ, Mathews TJ. Births: final data for 2011. Natl Vital Stat Rep. 2013;62(1):1-69,72.

25. Kulkarni AD, Jamieson DJ, Jones Jr HW, Kissin DM, Gallo MF, Macaluso $\mathrm{M}$, et al. Fertility treatments and multiple births in the United States. N Engl J Med. 2013;369(23):2218-25.

26. Sabzehei MK, Basiri B, Shokouhi M, Eghbalian F. Perinatal outcome in multiple versus single pregnancies of neonates born in Fatemieh Hospital of Hamadan, Iran. Int J Pediatr. 2017;5(8):5493-500.

27. Kavehmanesh Z, Amirsalari S, Torkaman M, Matinzadeh ZK, Haghiri $M$, Javadipour $M$. Frequency of multiple pregnancy and its complications in three educational hospitals, Tehran. Iran J Pediatr. 2006;17(Suppl 2):261-7.

28. Mosayebi Z, Movahedian AH, Mir Talaei B. The prevalence of Multiple pregnancy and complications leading to hospitalization in infants born Shahidbeheshti and Shabihkhani Hospital 20002001 years, Kashan, Iran. Feyz, J Kashan U Med Sci. 2003;26:7784.

29. Mohangoo AD, Blondel B, Gissler M, Velebil P, Macfarlane A, Zeitlin J, et al. International comparisons of fetal and neonatal mortality rates in high-income countries: should exclusion thresholds be based on birth weight or gestational age? PLoS One. 2013;8(5):e64869.

30. Chaudhary S, Singh RR, Shah GS, Agrawal J, Kafle S, Shah L. Outcome of twin deliveries at a Tertiary Care Centre of Eastern Nepal. J Nepal Health Res Counc 2016;14(33):128-31. 